\title{
Pharmacology and therapeutics
}

\section{Laser treatment for further depigmentation in vitiligo}

\author{
Monique Thissen, MD, and Wiete Westerhof, MD
}

From the Netherlands Institute for Pigmentary Disorders (NIP), Amsterdam, The Netherlands

\author{
Correspondence \\ Wiete Westerhof, MD \\ Meibergdreef 35 \\ 1105 AZ Amsterdam ZO \\ The Netherlands
}

Drug name

hydroquinone monobenzylether:

Benoquin

\begin{abstract}
Background In patients with vitiligo, sometimes the greatest part of the skin has already lost its melanocytes. The remaining pigmented patches can be removed by using strong bleaching creams, but many adverse events have been reported with this treatment. A new depigmentation therapy could be treatment with a Ruby laser.

Methods Before treatment, the patients filled out a questionnaire about their vitiligo history. Eight patients with remaining pigmentation of the arms, hands, and face were treated once with a Ruby laser. Patients were monitored for developing repigmentation during the 9 months after treatment.

Results In patients with a positive Koebner phenomenon, a permanent state of depigmentation was reached after laser therapy. None of the treated patients showed severe side-effects.

Conclusions Ruby laser treatment can be an effective, fast, and safe method for removing cosmetically disturbing remnants of normal pigmentation in vitiligo patients with a positive Koebner phenomenon.
\end{abstract}

Vitiligo is a common, acquired skin disease with an estimated incidence of $0.5 \%-\mathrm{I} \%$. It is characterized by circumscribed macules of amelanosis caused by destruction of the melanocytes. In the pathogenesis of this disorder, the autoimmune, the neural, and the self-destructive hypotheses are well known. ${ }^{\mathrm{I}-3}$ The process may be localized to one circumscribed area, or it may be distributed symmetrically on the trunk and the extremities, although a very extensive type may also develop.

Treatment options such as psoralen-ultraviolet A (PUVA) therapy, steroid cream locally, and pigment-cell transplantation techniques are aimed at creating repigmentation. In very extensive vitiligo, repigmentation therapy is seldom effective. The remaining pigmented patches may cause serious psychologic problems, especially in patients with a dark skin. Such pigmented areas can be removed by using a depigmentation cream for between 6 and I 2 months. Unfortunately, in some cases the bleaching cream fails to cause any depigmentation and severe irritation of the skin has often been reported. Recently, for depigmentation, we have used a Ruby laser that is capable of selectively destroying melanocytes.

\section{Materials and methods}

Eight healthy vitiligo patients (five women and three men, aged between 10 and 69 years) with residual pigmentations on the hands, arms, and face, were treated once with a Q-Switched Ruby laser, Lambda type (694 nm). All patients had been treated before with a bleaching cream containing 4methoxyphenol, but without success.

\section{Study design}

The study was an open, noncomparative clinical trial to evaluate the efficacy and safety of depigmentation using Ruby laser treatment. Patients were asked to fill out a questionnaire which included age on onset of vitiligo, provoking factors, family history, and work history. Informed written consent was obtained from each person.

The patients were treated once with energy densities varying from 10 to $40 \mathrm{~J} / \mathrm{cm}^{2}$, according to skin type. Treated skin was covered with sterile gauze and patients were told to avoid exposure to sunlight for 6 weeks. Follow-up visits took place at 3,6 , and 9 months after treatment.

\section{Results}

The mean age of the patients was 32.8 years and the mean duration of the disease was 14.5 years. Depigmentation was obvious within 7 days in all subjects. The treatment was painful in four patients; there were no other significant 
adverse events. During a follow up period of 9 months, follicular depigmentation developed in five patients. This was probably related to migration to the surface of residual melanocytes that had been localized in the epidermal appendages. In three patients, who also mentioned a positive Koebner phenomenon in the questionnaire, the treated areas remained depigmented (Fig. I). Table I summarizes the main results.

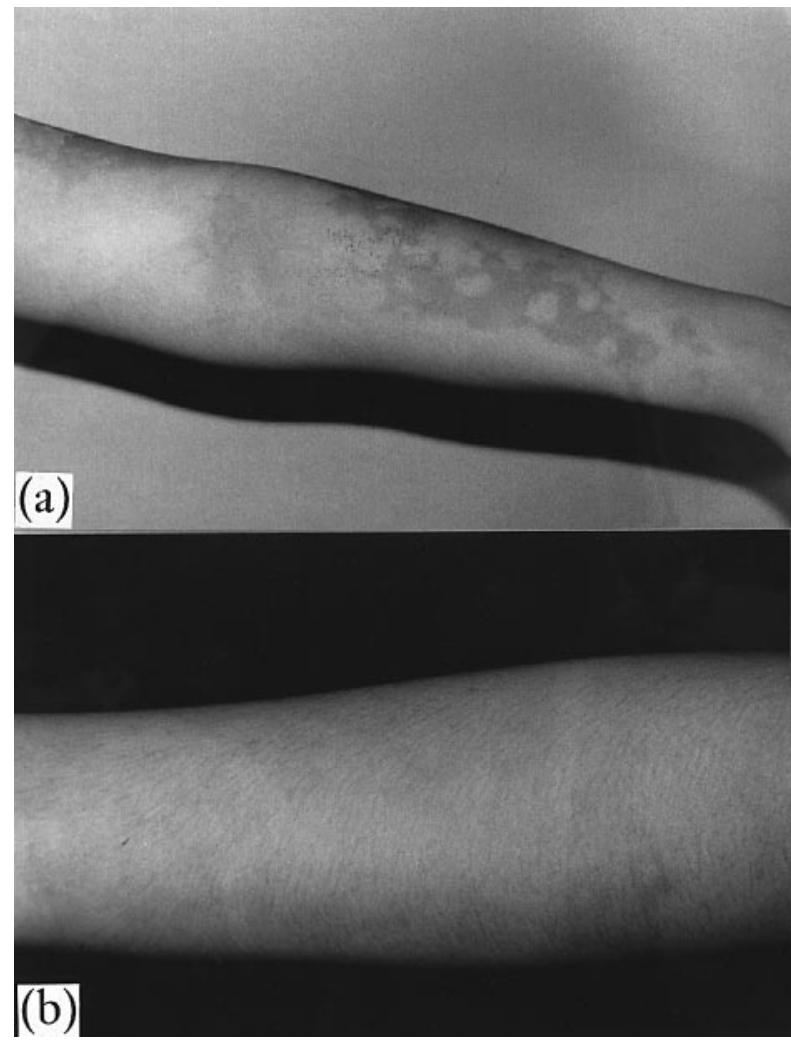

Figure 1 Left and right arm of patient 3 (Table I): (a) before laser treatment, (b) after laser treatment

\section{Discussion}

When none of the therapy options for repigmentation in patients with vitiligo are successful and the skin has already become over $80 \%$ depigmented, both dermatologist and patient may decide to attempt to remove the remaining pigmentations. In general, this is a point of no return. Protection from the sun will be necessary for the rest of the patient's life. ${ }^{4}$

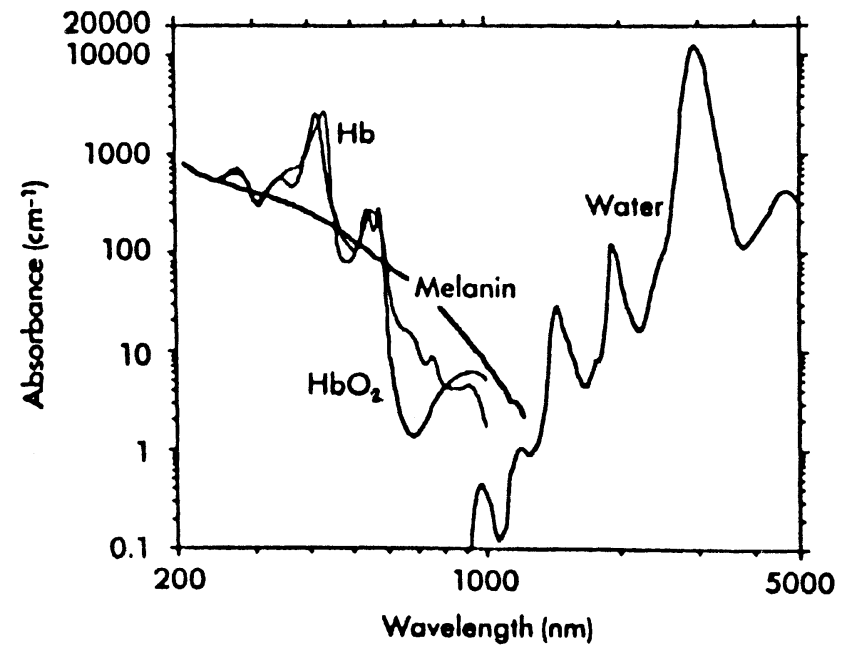

Figure 2 Absorption coefficients of melanin at different wave lengths (adapted from Goldman MP, Fitzpatrick RE.

Cutaneous Laser Surgery. St Louis: Mosby Yearbook, I994: I-I 8.)

Table 1 History of vitiligo and results of laser therapy in the treated study cases

\begin{tabular}{|c|c|c|c|c|c|c|c|c|}
\hline \multirow{3}{*}{ Patient } & \multirow{3}{*}{ Age } & \multirow{3}{*}{ Sex } & \multicolumn{3}{|c|}{ History of vitiligo } & \multicolumn{3}{|c|}{ Laser treatment results } \\
\hline & & & \multirow{2}{*}{ Age at onset } & \multirow{2}{*}{$\begin{array}{l}\text { Koebner } \\
\text { Phenomenon }\end{array}$} & \multirow{2}{*}{$\begin{array}{l}\text { Autoimmune } \\
\text { Disease }\end{array}$} & \multirow{2}{*}{ Depigmentation } & \multicolumn{2}{|c|}{ Side-effects } \\
\hline & & & & & & & Pain & Scarring \\
\hline 1 & 14 & M & 4 & - & - & - & + & - \\
\hline 2 & 46 & M & 38 & - & - & - & - & - \\
\hline 3 & 20 & W & 12 & + & - & + & - & - \\
\hline 4 & 30 & W & 15 & - & - & - & + & - \\
\hline 5 & 10 & W & 4 & - & - & - & + & - \\
\hline 6 & 36 & W & 4 & + & - & + & - & - \\
\hline 7 & 69 & W & 45 & - & - & - & + & - \\
\hline 8 & 38 & $M$ & 25 & + & - & + & - & - \\
\hline
\end{tabular}


Destroying the melanocytes in the residual pigmentations is possible by the daily use locally of the bleaching substance 4-methoxyphenol or the monobenzylether of hydroquinone. ${ }^{5}$ A small fraction of the cream will reach the bloodstream after transcutaneous uptake; thus there is a risk of damage to other melanocyte-containing structures (e.g. eyes and neurocutaneous structures) and all types of collagen. ${ }^{6}$ To minimize this risk the cream should be applied in small amounts. Side-effects such as severe redness, burning, and itching often occur. It is obvious that depigmentation is not easy to achieve

We have attempted to destroy melanocytes by using a Q-switched Ruby laser. The lightbeam, with a wavelength in the red region, is capable of penetrating deep into the dermal layer. The coefficient of absorption of the melanin chromophore is high for laser-light at a wavelength of 694 $\mathrm{nm}$ (Fig. 2). Because the duration of the energy pulse is shorter than the thermal relaxation time of melanosomes, no energy (i.e. heat) will be transduced into the surrounding tissue. Further cell damage and scar formation will rarely be seen. ${ }^{7}$

Only the three patients who mentioned a positive Koebner phenomenon remained depigmented after laser therapy. ${ }^{8}$ Laser treatment can also be considered as a stimulus to induce the Koebner phenomenon. This aspect could be important in deciding whether to produce depigmentation in the patient by laser therapy.

\section{Conclusions}

Compared with bleaching of the skin with a local depigmentation cream, laser therapy is effective after a single treatment and shows no persistent side-effects.

\section{References}

I Bolognia JL, Pawelek JM. Biology of pigmentation. J am Acad Dermatol I988; 19: 217-255.

2 Bose SK. Segmental vitiligo, nevus anemicus and catecholamines: what's the relation? Biogenic Amines I994; I0: 239-246.

3 Lerner AB. On the etiology of vitiligo and grey hair. Am J Med I97I; 5I: I4I-I47.

4 Mosher DB. Disorders of melanocytes. In: Fitzpatrick TB, Eisen AZ, eds. Dermatology in General Medicine. $4^{\text {th }}$ edn. New York: McGraw Hill, I993: 923-933.

5 Mosher DB. Monobenzylether of hydroquinone: a retrospective study of $\mathrm{I} 8$ severely affected vitiligo patients. Br J Dermatol I977; 97: 669-679.

6 Riley PA. Pathological disturbance of pigmentation. In: Jarret A, ed. Pathology and Pathophysiology of the Skin. Vol. 3. New York: Academic Press, I974: I I67-II97.

7 Goldman MP, Fitzpatric RE. Laser-tissue interaction. In: Cutaneous Laser Surgery. St Louis: Mosby Yearbook, I994: I-I8.

8 Sweet RD. Vitiligo as a Koebner phenomenon. $\mathrm{Br} J$ Dermatol I978; 99: 223-224.

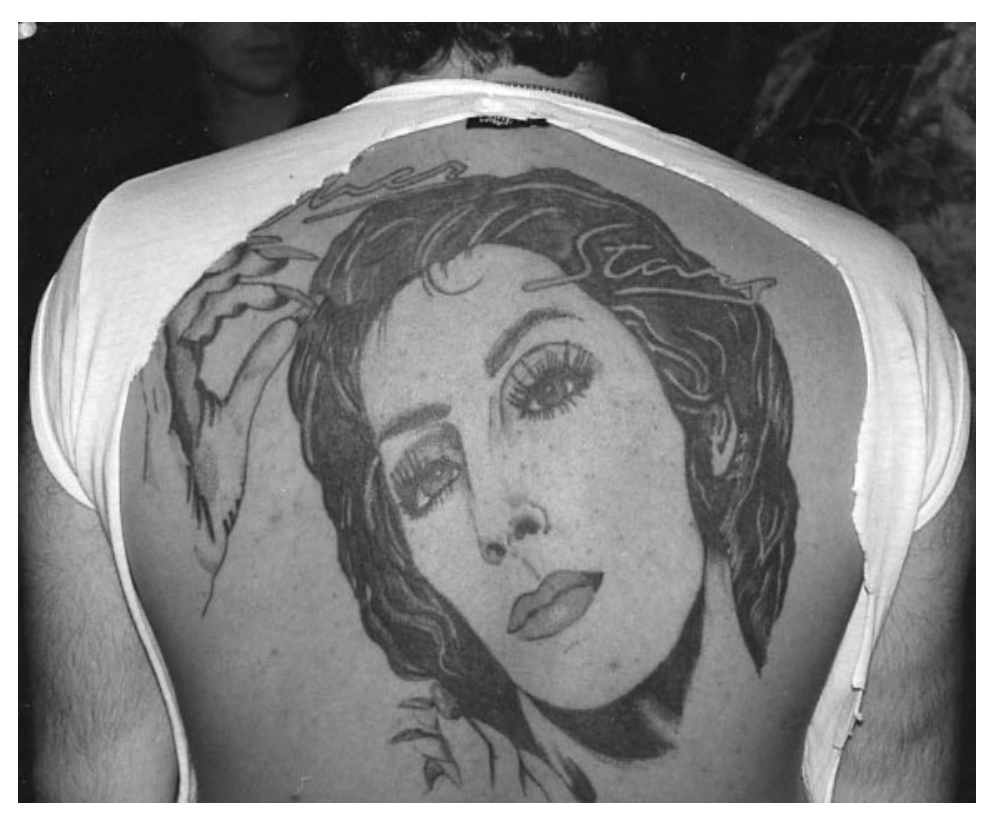

Tattoo art by Doug Hardy of the China Sea Tattoo Studio, Honoloulu, Hawaii, from the collection of Norman Goldstein, MD (dubbed the "tattoo guru" by Charles Grupper, MD, University of Paris) - The World of Tattoos, Honolulu, Hawaii. 